\title{
Characterization of Mushroom Strains on the Basis of Physiological Conditions and Enzymatic Activity
}

\author{
Rati Satish Chunletia ${ }^{1}$, Mithilesh Kumar ${ }^{2 *}$ and Dayaram ${ }^{3}$ \\ ${ }^{2}$ Dr. Rajendra Prasad Central Agricultural University, Pusa (Bihar), India \\ ${ }^{3}$ Department of Micro Biology, Dr. Rajendra Prasad Central Agricultural University, \\ Pusa (Bihar), India \\ *Corresponding author
}

\section{A B S T R A C T}

\section{Keywords}

Mushroom, Genera,

Biochemical,

Physiological, Characterization

\section{Article Info}

\section{Accepted:}

15 February 2020 Available Online: 10 March 2020
A study on 18 strains of mushrooms belonging to 5 genera namely Agaricus, Calocybe, Lentinula, Pleurotus, Tricholomawas done for biochemical and physiological studies. These strains were obtained from Directorate of Mushroom Research, Solan and Mushroom Lab, RPCAU, Pusa. Radial growth measurement of mycelium for optimum growth conditions for all the strains were recorded with respect to different media, temperature and $\mathrm{pH}$. The biochemical screening of enzymatic activities for all the strains was also done for lipase, amylase, laccase and oxidase.

\section{Introduction}

Just the way a seed needs proper environment to grow, microorganisms need nutrients, a source of energy and certain environmental conditions in order to grow and reproduce (Ravimannan et al., 2014). Growth in pure mycelium culture in a solid medium is the first step of cultivation of edible mushrooms. Mycelial growth into a solid substrate is affected by various factors, including temperature, $\mathrm{pH}$, nutrient ingredients and environmental factors (Imtiaj et al., 2008), the time required for the growth of mycelium on a solid medium is relatively short, and thus an accurate and quick assessment can be facilitated. Therefore, the quality and quantity of a mushroom strain mycelium in a solid medium is one of the most important matrices to determine further nutritional requirements for the production of fruiting bodies of the mushroom. (Masoumi, 2015) and mycelial growth rate could be used as a criterion to select for fast-growing isolates, as it is 
assumed that mushroom fast-growing strains colonize compost or casing layer much faster and achieve high production yields compared to the slower strains (Guadarrama-Mendoza et al., 2014).

During the growth of mushroom mycelia and the development to mature fruitbodies (or sporophores), biochemical changes are known to occur, as a result of which enzymes are secreted extracellularly to degrade the insoluble materials in the substrates into simple and soluble molecules which are subsequently utilized by intracellular enzymes within the mushroom. Consequently, enzymes play significant role in mushroom development; in addition, they also affect the food nutrient, flavour and shelf life of these fungi (Baardseth, 1979; Paranjpe and Chen, 1979; Wang, 1989; Zadrazil et al., 2004; Kuforiji and Fasidi, 2008; Kapoor et al., 2009). It is considered that, with few exceptions, ectomycorrhizal Basidiomycota do not have enzymes that can degrade cellulose and lignin (Hutchison 1990; Tedersoo et al., 2010), although in this respect, final conclusions have not yet been drawn. However, some ectomycorrhizal fungi, such as Tricholoma aurantium, Amanita muscaria, Rhizopogon luteolus, Rhizopogon roseolus and Cenococcum geophylum (Trojanowski et al., 1984), are able to degrade lignin and cellulose, so they act as successful competitors to saprotrophs (Koide et al., 2008; Dames et al., 1999). Due to this ability, some ectomycorrhizal fungi are able to survive after lengthy dry periods or harmful disturbances in the ecosystem (Dames et al., 1999).

\section{Materials and Methods}

\section{Fungal material}

The morphological and cultural characteristics of vegetative mycelium of 18 mushroom strains were investigated for morphological, cultural and biochemical characterization. The fungal materials were maintained by sub-culturing throughout the study (Table.1.)

\section{Media}

Six different media were used for the study viz. Potato Dextrose Agar (PDA), Wheat extract Agar (WEA)and Malt Extract Agar (MEA), Starch Agar Medium (For Amylase Test), Lipase Test Medium, Laccase Test Medium.

\section{Oxidase discs}

Oxidase test was performed using oxidase discs from Micromaster Laboratories Pvt. Ltd. The wet discs would change color within seconds of coming in contact with the culture as a positive test for oxidase.

\section{Results and Discussion}

\section{Media}

The radial growth(mm) was calculated on 3 different media viz. Potato Dextrose Agar, Wheat extract Agar and Malt Extract Agar after 7 days of inoculation in 3 replicates. Highest radial growth was observed in PL-1702 in WEA which was at par with PL-17-01 in the same medium. Among all the strains PL-17-02 showed the best radial growth and WEA was statistically the best medium. It was observed that Tricholoma strains achieved the best radial growth on PDA (50 $\mathrm{mm}$ by CiP-18 and $39 \mathrm{~mm}$ by CiP-19) followed by WEA and least on MEA. Agaricus strains grew best on MEA (AB-1401 and AB-16-02 attained $19 \mathrm{~mm}$ ) followed by PDA. Lentinula strains grew best on PDA ranging from $34 \mathrm{~mm}$ in LE-1503 to $40 \mathrm{~mm}$ in LE-15-01 and LE-15-04 followed by WEA (Figure 1). 


\section{Temperature}

The radial growth $(\mathrm{mm})$ was calculated after 7 days of inoculation on 3 replicates of PDA medium for 6 different temperature ranging from $15^{\circ} \mathrm{C}$ to $40^{\circ} \mathrm{C}$ with a difference of 5 degrees. Highest radial growth was observed in $\mathrm{PF}$ at $15^{\circ} \mathrm{C}$ which was at par with $\mathrm{PD}$ at the same temperature and PF and PL-17-03 at $20^{\circ} \mathrm{C}$. Among all the strains PF and PL-17-03 showed the best radial growth and $15^{\circ} \mathrm{C}$ was statistically the best temperature (Figure 2).

It was observed that Tricholoma strains achieved the best radial growth at $25^{\circ} \mathrm{C}$ (50 $\mathrm{mm}$ by $\mathrm{CiP}-18$ and $39 \mathrm{~mm}$ by $\mathrm{CiP}-19)$ and least at $15^{\circ} \mathrm{C}$. It showed more than average growth even at $40^{\circ} \mathrm{C}$. Agaricus strains on an average showed best results at $25^{\circ} \mathrm{C}(\mathrm{AB}-14$ 01 and $A B-16-02$ attained $19 \mathrm{~mm}$ and $18 \mathrm{~mm}$ respectively) but these strains individually had different best temperatures i.e. $15^{\circ} \mathrm{C}$ for $\mathrm{AB}-16-02$ and $20^{\circ} \mathrm{C}$ for $\mathrm{AB}-14-01$. Lentinula strains grew best at $15^{\circ} \mathrm{C}$ with their radial growth ranging from $64 \mathrm{~mm}$ in LE-15-03 to $57 \mathrm{~mm}$ in LE-15-01. The growth declined with decrease in temperature and no growth was observed at $40^{\circ} \mathrm{C}$. Calocybe strains attained maximum growth at $25^{\circ} \mathrm{C}$ with highest growth of $45 \mathrm{~mm}$ in CI-17-04 followed by $43 \mathrm{~mm}$ by CI-17-06 and $40 \mathrm{~mm}$ by CI-17-02. Individually $30^{\circ} \mathrm{C}$ was found best for CI-17-02 and C-17-04. Pleurotus strains grew at all the six temperatures with an average growth more than all the other strains but statistically grew best at $15^{\circ} \mathrm{C}$ showing a growth range from $83 \mathrm{~mm}$ in PL17-01 to $90 \mathrm{~mm}$ in PD and PF, however the best temperature for strain PL-17-03 was found to be $20^{\circ} \mathrm{C}$ with $90 \mathrm{~mm}$ of radial growth.

\section{pH}

Highest radial growth was observed in PF at $\mathrm{pH}$ 9. Among all the strains PL-17-03 showed the best radial growth and $\mathrm{pH} 7$ was statistically the best $\mathrm{pH}$. The Tricholoma strains achieved the best radial growth at $\mathrm{pH} 9$ ( $50 \mathrm{~mm}$ by CiP-18 and $49 \mathrm{~mm}$ by CiP-19) followed by $\mathrm{pH}$ 7.It showed more than average growth even at $\mathrm{pH}$ 5. Agaricus strains attained best results at $\mathrm{pH} 9$ (AB-14-01 and AB-16-02 attained $19 \mathrm{~mm}$ and $23 \mathrm{~mm}$ respectively).They showed more than average growth even at $\mathrm{pH}$ 5. Lentinula strains were found to be $\mathrm{pH}$ sensitive and did not grow at $\mathrm{pH} 5$ and $\mathrm{pH}$ 9, attained growth only at $\mathrm{pH} 7$ ranging from $40 \mathrm{~mm}$ in LE-1501 and LE-1504 to $34 \mathrm{~mm}$ in LE-15-03. Calocybe strains attained maximum growth at $\mathrm{pH} 7$ with highest growth of $45 \mathrm{~mm}$ in CI-17-04 followed by $43 \mathrm{~mm}$ by CI-17-06 and $40 \mathrm{~mm}$ by CI-17-02 but individually $\mathrm{pH} 9$ was best for CI-17-02 as it attained growth of $42 \mathrm{~mm}$. Pleurotus strains on an average grew best at $\mathrm{pH} 9$ showing a range of growth from $85 \mathrm{~mm}$ in PF to $70 \mathrm{~mm}$ in PSC, however the best $\mathrm{pH}$ for strain PD was found to be $\mathrm{pH} 7$ with 60 $\mathrm{mm}$ of radial growth(Figure. 3 ).

\section{Biochemical test}

Enzymatic screening of mushroom strains was qualitatively done using differential agar plates and oxidation discs. A total of four tests pertaining to different activities was done on mushroom mycelium. The measurement of reaction by the strains was denoted by ' - ' for absence of the enzymatic activity, '+' for presence, '++'for strongly present, ' +++ ' very strongly present and ' ++++ ' for excellent activity. The results of the experiments have been represented in Table 1.The positive test for each enzyme were as follows; for amylase the zone of clearance against iodine was checked; fragmentation of agar plate was observed for lipase test; the change in color of oxidase disc for oxidase test and pigmentation for the laccase test (Figure 4).

All the strains of Pleurotus and Calocybe showed positive test for amylase activity whereas all the strains of Tricholoma, 
Lentinula and Agaricus showed negative results with $\mathrm{AB}-14-01$ as an exception. Lipase was the only enzyme whose activity was found to be present in all the strains as it showed positive results for all the strains. Most of the strains were oxidase positive except for LE-15-03 and LE-1504. All the strains showed positive Laccase test except for three strain viz. CiP-18, CI-17-04, PL-1701. AB-14-01 was found to be the strain with the best enzymatic activity followed by PF-1 and CI-17-06.

Table.1 List and source of strains used in the study

\begin{tabular}{|l|l|l|l|}
\hline Sr.No. & Strain & Species & Source \\
\hline $\mathbf{1}$ & CiP18 & Tricholoma giganteum & R.P.C.A.U, Pusa \\
\hline $\mathbf{2}$ & CiP19 & Tricholoma giganteum & R.P.C.A.U, Pusa \\
\hline $\mathbf{3}$ & AB-14-01 & Agaricus bisporus & R.P.C.A.U, Pusa \\
\hline $\mathbf{4}$ & AB-16-02 & Agaricus bisporus & R.P.C.A.U, Pusa \\
\hline $\mathbf{5}$ & LE-15-01 & Lentinula edodes & D.M.R, Solan \\
\hline $\mathbf{6}$ & LE-15-02 & Lentinula edodes & D.M.R, Solan \\
\hline $\mathbf{7}$ & LE-15-03 & Lentinula edodes & D.M.R, Solan \\
\hline $\mathbf{8}$ & LE-15-04 & Lentinula edodes & D.M.R, Solan \\
\hline $\mathbf{9}$ & CI-17-02 & Calocybe indica & D.M.R, Solan \\
\hline $\mathbf{1 0}$ & CI-17-04 & Calocybe indica & D.M.R, Solan \\
\hline $\mathbf{1 1}$ & CI-17-06 & Calocybe indica & D.M.R, Solan \\
\hline $\mathbf{1 2}$ & PL-17-01 & Pleurotus florida & D.M.R, Solan \\
\hline $\mathbf{1 3}$ & PL-17-02 & Pleurotus florida & D.M.R, Solan \\
\hline $\mathbf{1 4}$ & PL-17-03 & Pleurotussajor-caju & D.M.R, Solan \\
\hline $\mathbf{1 5}$ & PF & Pleurotus florida & R.P.C.A.U, Pusa \\
\hline $\mathbf{1 6}$ & PF-1 & Pleurotus florida & R.P.C.A.U, Pusa \\
\hline $\mathbf{1 7}$ & PD & Pleurotus djamor & R.P.C.A.U, Pusa \\
\hline $\mathbf{1 8}$ & PSC & Pleurotus sajor- caju & R.P.C.A.U, Pusa \\
\hline
\end{tabular}

Figure.1 Radial growth (mm) of mushroom strains at different media

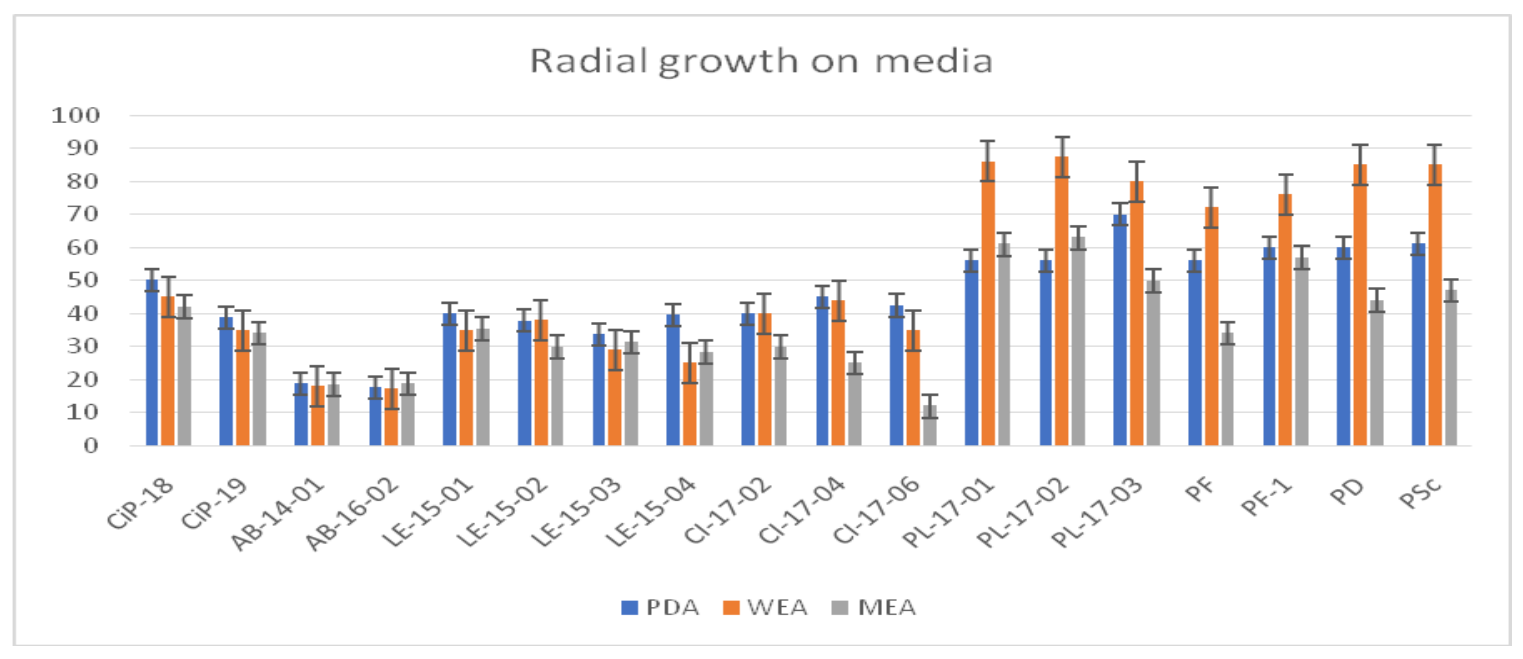


Figure.2 Radial growth (mm) of mushroom strains at different temperature

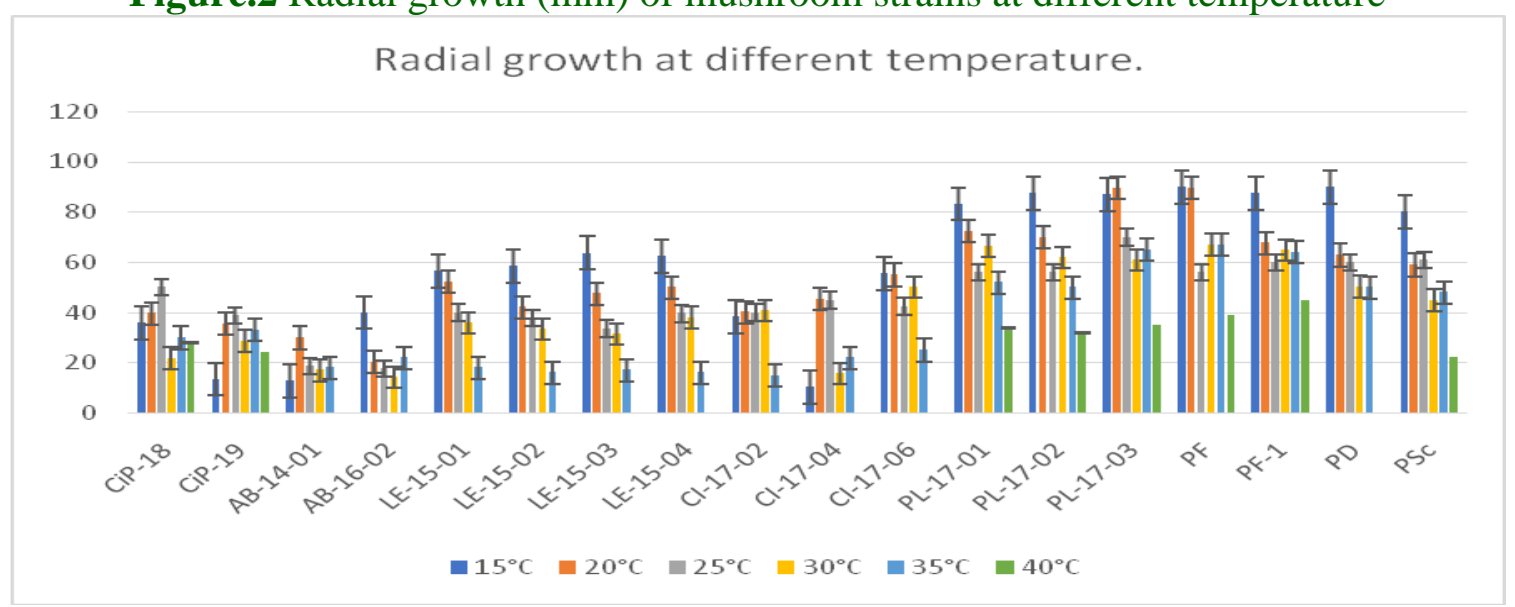

Figure.3 Radial growth (mm) of mushroom strains at different $\mathrm{pH}$

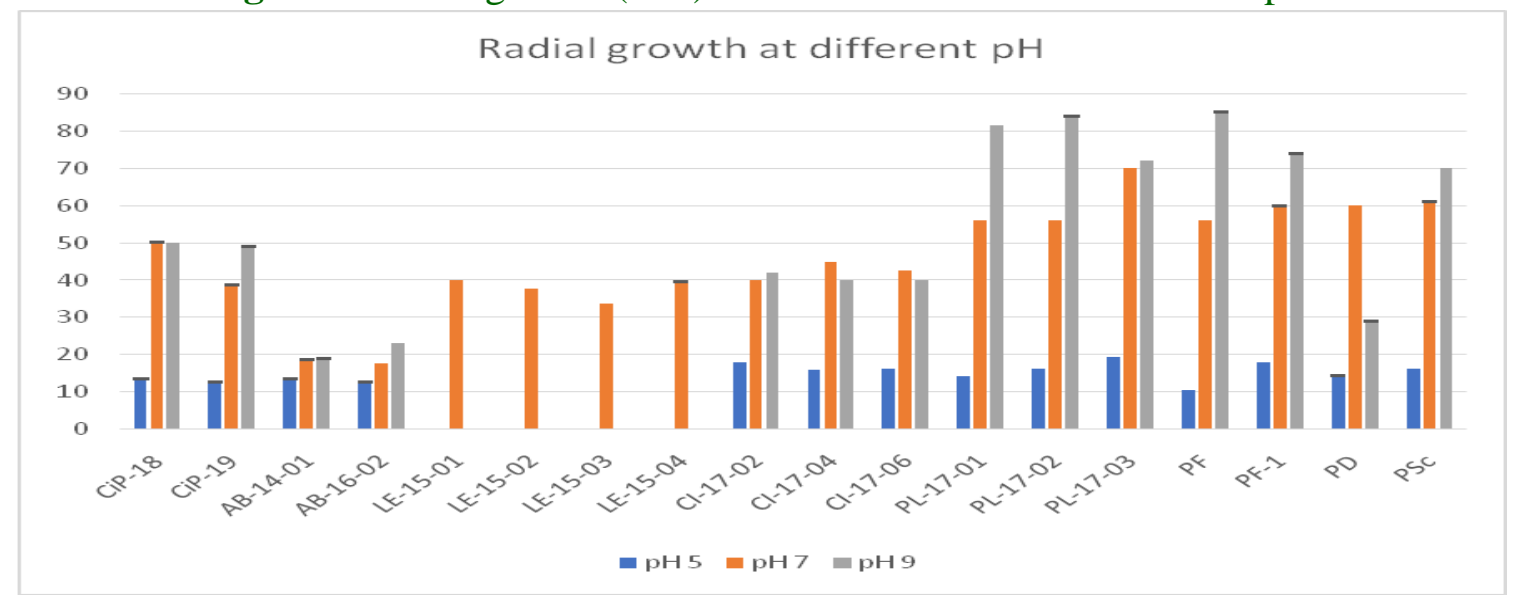

Figure.4 Biochemical tests

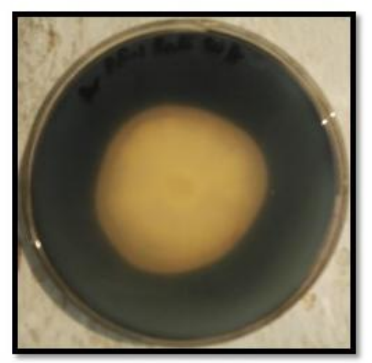

Amylase

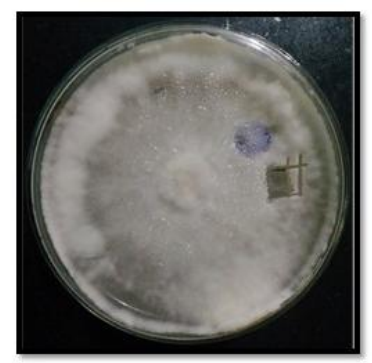

Oxidase

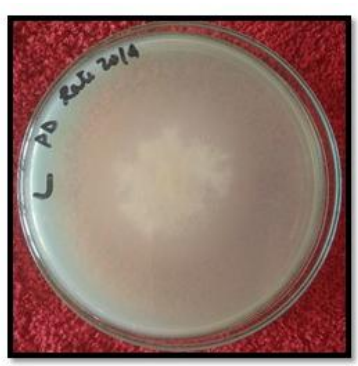

Lipase

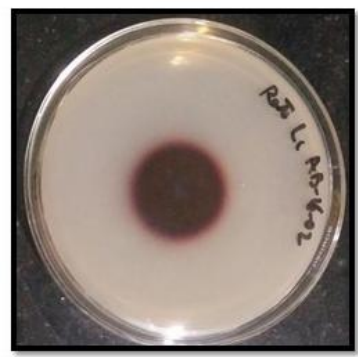

Laccase 


\section{Media}

The difference of mycelial growth on different agar media may be due to availability of different carbon sources and other required nutrients (Sardar, 2017). Growth of Tricholoma on different media was not reported earlier. The results for Agaricus deviated from Furlan et al., (1997), who investigated higher on WDA (wheat/dextrose/agar) medium than on PDA (potato/dextrose/agar) or MPA (malt/ Soya peptone/agar) media in all strains. Lentinula strains results are comparable to that of Arif et al., (2015) and Gbolagade et al., (2006) findings, who observed that potato dextrose agar is best for the culture establishment of shiitake mushroom. The present findings for Calocybe are almost similar to the results obtained by Singh et al., (2009), they reported that C.indica grew well on all the tested media but maximum growth was attained on WEA followed by PDA. Pleurotus strains results show a little deviation with the findings of Gibriell et al., (1996); Hussain and Hussain, (2004) who reported that Pleurotus spp. showed fastest growth of mycelium on potato dextrose agar among different media used. The effect of carbon sources on mycelium growth depends on the fungal strains, its comparison of the growth of strains in solid media shows the presence of significant differences and erratic growth patterns between them (Akata et al., 2012).

\section{Temperature}

The results for Tricholomawere similar to previous study which stated that $T$. imbricatum, T. batchii and L. deliciosus, were more thermophilic and grew faster at $25^{\circ} \mathrm{C}$ (Lazarević, 2016). Agaricus strains had results similar to Yadav (2014) which reported temperature of $25^{\circ} \mathrm{C}$ as more favorable to the mycelium growth of all A. bisporus strains. Lentinula results deviated from the present study as Lentinula edodes Le-17-04 grew best $24^{\circ} \mathrm{C}$ (Kumar, 2019) as presently standardized cultural conditions for shiitake mushroom is unavailable (Kumar, 2019).The results for Calocybe strains are in accordance with the findings of Varshney (2007) and Kerketta (2017) who reported that of $25-35^{\circ} \mathrm{C}$ is the optimum temperature requirement for mycelial growth in $C$. indica while Shukla et al., (2013) reported that $30^{\circ} \mathrm{C}$ was the best temperature for C.indica. Calocybe strain findings were a little similar to Wei et al., (2002) who reported a temperature range of $20-31^{\circ} \mathrm{C}$ for the hyphal growth of $P$. flabellatus and concluded that a temperature of $25^{\circ} \mathrm{C}$ is the optimum. Similarly, Zharare et al., (2010) found that P.sajor-caju can tolerate high $35^{\circ} \mathrm{C}$ temperature.

\section{pH}

$\mathrm{pH}$ is important to study for the growth of mycelium $\mathrm{pH}$ and temperature effects the growth of mushroom through affecting the enzyme activity in the cell (Sopit, 2006);

The results for Tricholoma were almost similar to Lazarević (2016) stated that examined isolates were tolerant to different $\mathrm{pH}$ values, but all of them grew more rapidly at $\mathrm{pH} 5.8$, consistent with the $\mathrm{pH}$ values measured at the sampling locality, thus the strains may have a change in $\mathrm{pH}$ with the change in locality. Agaricus strain results mirrored with Yadav (2014) as mycelial growth on $9 \mathrm{pH}$ was fastest for all A.bisporus strains. Lentinula strains had similar findings to Arif et al., (2015) which showed best mycelial growth of shiitake mushroom on 6 $\mathrm{pH}$ but statistically it was at par with $7 \mathrm{pH}$ and almost all mushrooms perform and grow best at neutral $\mathrm{pH}$ (Khan et al., 2013). The results or Calocybehave been very similar with the findings of Singh et al., (2015), Shukla and Jaitly (2013) and Varshney (2007) 
maximum mycelial growth was at $\mathrm{pH} 7.5$ followed by $\mathrm{pH} 8$. Some Pleurotus spp. are characterized for wider growth adaptability scale for $\mathrm{pH}$ i.e. 5-8 as reported by Yadav (2001). The mycelial growth of $P$. ostreatus was recorded best at $\mathrm{pH} 7.0$ by Bugarski et al., (2000). Singh (2017) reported that 7.5 was the best $\mathrm{pH}$ for the growth of $P$. djamor.

\section{Biochemical Studies}

Positive results for amylase can be explained as the examined isolates were capable of growing on polysaccharides, such as dextrin and starch, indicating the presence of enzymes that are able to carry out their decomposition to glucose (Lazarević, 2016). Lipase was the most effective enzyme for all the strains, it has been so consistent that Lipase was isolated from oyster mushroom (Wijayati et al., 2017) also. Most of the strains were oxidase positive except for LE15-03 and LE-15-04. However, it was difficult to track previous finding with respect to oxidase test in all the species. All the strains showed positive Laccase test except for three strain viz. CiP-18, CI-17-04, PL-1701. It is a white rot basidiomycete which belongs to the subclass of ligninolytic microorganisms that produce laccases, manganese peroxidases, amylase, cellulase, pectinase and protease (Rashad and Abdou, 2001; Palmieri et al., 2001; Abdou, 2003; Fan et al., 2008 and Rashad et al., 2009) This supports the present finding as all the strains under study belong to Basidiomycete. In previous studies also some strains showed negative test for laccase as mentioned by Kalmis (2008).

In conclusion, the optimum media, temperature and $\mathrm{pH}$ for the growth of mushroom strains used in the study was dependent on the strain of mushroom. The optimum growth conditions for Tricholoma strains were PDA medium, $25^{\circ} \mathrm{C}$ of temperature and $\mathrm{pH} 9$ while for Agaricus MEA medium, $25^{\circ} \mathrm{C}$ of temperature and $\mathrm{pH} 9$ were more appropriate. PDA medium, $15^{\circ} \mathrm{C}$ temperature and $\mathrm{pH} 7$ was suitable for Lentinula strains and WEA medium, $15^{\circ} \mathrm{C}$ temperature and $\mathrm{pH} 9$ for Pleurotus strains. Calocybe strains showed best growth on both PDA and WEA, at $25^{\circ} \mathrm{C}$ and $\mathrm{pH} 7$. Overall the best media for all the strains was WEA, best temperature $15^{\circ} \mathrm{C}$ and best $\mathrm{pH}$ was 7 . Based on the present study Lentinula strains were identified to be $\mathrm{pH}$ sensitive.

Most of the strains showed positive results for lipase, oxidase and laccase activity. All the strains of Pleurotus and Calocybe showed positive results for amylase activity however it was absent in the strains of Tricholoma and Lenitnula. The strain AB-14-01 of Agaricus was identified as the best strain for all the enzymes. As AB-14-01 showed maximum enzymatic activity, it can be used for bioremediation.

\section{References}

Akata, Ilgaz., Kalyoncu, Fatih., Solak, M. Halil and Kalmış, Erbil (2012). Growth of mycelium of three ectomycorrhizal macrofungi, Infundibulicybegeotropa, Tricholoma anatolicum and Lactarius deliciosus in culture media containing various carbon sources. African Journal of Microbiology Research 6(12): 30423046.

Guadarrama-Mendoza, P.C., Toro, G. V., Carrillo, R. R., Martínez, F. R., Fernández, J. Y., Aguilar, M.E. G., and Villa, G. B. (2014). Morphology and mycelial growth rate of Pleurotus spp. strains from the Mexican mixtec region. Brazilian Journal of Microbiology, 45(3): 861-872.

Imtiaj, A., Alam, S., and Lee, T. S. (2008). Mycelial propagation of Agrocybe cylindracea strains collected from 
different ecological environments. Bangladesh Journal of Mushroom 2(1): $35-42$.

Kerketta, A., Singh, H.K. and Shukla, C.S. (2017). Assessment of Mycelial Growth and Yield Attribute of Calocybe indica $\mathrm{P}$ and $\mathrm{C}$. International Journal of Current Microbiology and Applied Sciences 6(12): 1082-1087.

Khan, M. W., Ali, M. A., Khan, N. A., Khan, M. A., Rehman, A. and Javed, N. (2013). Effect of different levels of lime and $\mathrm{pH}$ on mycelial growth and production efficiency of oyster mushroom (Pleurotus spp.). Pakistan Journal of Botany45: 297-302.

Kumar, V., Mishra, S.K. and Kaur, M. (2019). Effect of different media, temperature and $\mathrm{pH}$ on radial mycelial growth of Lentinula edodesstrain Le-1704. Journal of Pharmacognosy and Phytochemistry8(1): 345-348.

Lazarević, J., Stojičić, D., Keča, N. (2016). Effects of temperature, $\mathrm{pH}$ and carbon and nitrogen sources on growth of in vitro cultures of ectomycorrhizal isolates from Pinus heldreichii forest. Forest Systems 25(1): 48.

Masoumi, F., Pourianfar, H. R., Masoumi, A., Mendi, E. M. (2015). A study of mycelium characterization of several wild genotypes of the button mushroom from Iran. International Journal of Advanced Research 3(2): 236-246.

Ravimannan, N., Arulanantham, R., Pathmanathan S. and Niranjan, K. (2014). Alternative culture media for fungal growth using different formulation of protein sources. Annals of Biology Research 5: 36-39.

Sardar, H. A. A., Muhammad, A. A., Muhammad, N., Fahim, N., Aamir, H., Sajjad, N., Safina, K. and Sohail. (2017). Agro-industrial Residues Influence Mineral Elements Accumulation and Nutritional Composition of King Oyster Mushroom (Pleurotus eryngii). Scientia Horticulturae, 225 10.1016/j.scienta. 2017.07.010.

Singh, I., Nivedita, L. and Singh, C. (2009). Cultivation of Pleurotus spp. on agroforest wastes of Manipur. Indian Phytopathology62(1): 106-108.

Varshney, A. (2007). Variability among the strains of Calocybeindica (P\&C) MSc thesis, Govind Ballabh Pant University of Agriculture \& Technology, Pantnagar. Pp. 94.

Wijayati, N. et al., (2017). Oyster mushroom's lipase enzyme entrapment on calcium alginate as biocatalyst in the synthesis of lauryl diethanolamide. IOP Conf. Ser.: Mater. Sci. Eng. 172.

Yadav, M.K. and Chandra, R. (2014). Effect of Culture Media, $\mathrm{pH}$ and Temperature on Mycelial Growth of Agaricus Bisporus Strains. Journal of Pure and Applied Microbiology 8(3).

Zadrazil, F., G. Compare, R. and Maziero, (2004). Biology, cultivation and utilization of Pleurotus sp. In: science and cultivation of edible and medicinal fungi. Eds., Ringer, D.L. and D.J. Royse, Penn State, pp. 383-391.

\section{How to cite this article:}

Rati Satish Chunletia, Mithilesh Kumar and Dayaram. 2020. Characterization of Mushroom Strains on the Basis of Physiological Conditions and Enzymatic Activity. Int.J.Curr.Microbiol.App.Sci. 9(03): 1898-1905. doi: https://doi.org/10.20546/ijcmas.2020.903.220 